\title{
VESTIBULAR DA FUVEST E UNICAMP: ESPETÁCULO E NARRATIVA NA MÍDIA WEB ${ }^{1}$
}

\section{Resumo}

Denise Giarola Maia ${ }^{2}$

A proposta desse artigo é descrever o espetáculo do vestibular na mídia web, através de notícias sobre o exame de 2010 da Fuvest e Unicamp, e também identificar um percurso narrativo no noticiário sobre o vestibular. O material de pesquisa foi composto por notícias dos sites UOL, Globo.com, Estadao.com.br e Folha Online e da seção de entrevista do Jornal do Vestibulando e de um vídeo disponíveis nos sites dos cursinhos pré-vestibulares de São Paulo, Etapa e Anglo. A análise desses artefatos midiáticos foi fundamentada nos trabalhos de Debord (1997), Kellner (2006), Wolff (2005), Balogh (2002) e Dayan e Katz (1999).

Palavras-chave: Espetáculo, narrativa, mídia, vestibular.

\begin{abstract}
The purpose of this article is to describe the spectacle of the vestibular in web media, through news on the 2010 exam of Fuvest and Unicamp, and also identify a narrative journey in the news about Vestibular. The research material was composed of news published in sites like UOL, Globo.com, and Estadao.com.br BBC and an interview section in the Jornal do Vestibulando and a video available on the websites of two college preparatory courses of São Paulo, Etapa and Anglo. The analysis of these media artifacts was based on the work of Debord (1997), Kellner (2006), Wolff (2005), Balogh (2002), Dayan and Katz (1999).
\end{abstract}

Keywords: Spectacle, narrative, media, vestibular.

\section{Introdução}

A procura pelo ensino superior tem crescido nas últimas décadas, principalmente pelas mudanças no mercado de trabalho, que tem exigido cada vez mais uma mão de obra qualificada. Além disso, nossa sociedade sempre valorizou mais aquelas profissões nas quais o indivíduo exerce o intelecto. E, portanto, vivemos uma cultura dos títulos (meritocracia).

O ingresso ao ensino superior no Brasil acontece por meio de um processo seletivo denominado vestibular. Cada universidade possui uma instituição responsável pela elaboração do exame, ao qual se submetem os alunos que concluíram o ensino médio, e os aprovados com as melhores notas preenchem as vagas que são oferecidas por cada curso ${ }^{3}$. O vestibular é um evento noticioso para a mídia, pois se trata de um assunto de interesse comum e que remete a uma experiência pela qual quase todos já passaram, ainda vão passar, ou possui

\footnotetext{
${ }^{1}$ Este artigo foi elaborado a partir de um trabalho apresentado ao Prof. Dr. Guilherme Jorge de Rezende, no final da disciplina de Seminário de Práticas Discursivas: Elementos da Comunicação Midiática, do Programa de Mestrado de Teoria Literária e Crítica da Cultura da Universidade Federal de São João del-Rei (UFSJ).

${ }^{2}$ Graduada em Letras (licenciatura Português/Inglês) pela Universidade Federal de Viçosa (UFV) e mestre em Letras pela Universidade Federal de São João del-Rei (UFSJ).

${ }^{3} \mathrm{O}$ acesso às vagas em um curso de nível superior tem sofrido algumas mudanças. Hoje, o ingresso acontece também através do Sistema de Avaliação em larga escala do Ensino Médio, mais especificamente pelo ENEM (Exame Nacional do Ensino Médio).
} 
algum conhecido que esteja passando. Portanto, é um assunto familiar, isto é, que diz respeito a toda família e não somente ao candidato.

A proposta desse artigo é descrever o espetáculo do vestibular na web, através das notícias que foram postadas durante a realização dos exames de 2010 da Fuvest e Unicamp, e também identificar um percurso narrativo no noticiário e publicidade do vestibular.

Para isto, selecionamos notícias que foram postadas na web, mais especificamente nos sites UOL, Globo.com (G1, Jornal Nacional e Jornal Hoje), Estadao.com.br e Folha Online, sobre os vestibulares da Fundação Universitária para o Vestibular (FUVEST) e da Unicamp, além disso, analisaremos a seção entrevista do Jornal do Vestibulando e um vídeo, disponíveis para download nos sites de dois cursinho pré-vestibulares de São Paulo, Etapa e Anglo.

Optamos por selecionar o vestibular da FUVEST, responsável pelo processo seletivo da Universidade de São Paulo (USP), Faculdade de Ciências Médicas de Santa Casa de São Paulo e Academia da Polícia Militar do Barro Branco, e o vestibular da Unicamp, por serem os mais concorridos do país e terem uma cobertura em âmbito nacional. Contudo, isso não significa que apenas estes recebem destaque na mídia; ao contrário, em cidades do interior que possuem universidades, as mídias desses locais se voltam quase que exclusivamente para tal evento, às vezes, até promovendo festas.

Já o interesse pela web consiste no fato desse canal, além de permitir a expansão dos conteúdos num espaço geográfico a nível mundial e ter se popularizado, também reúne os diversos recursos semióticos (vídeo, áudio e texto verbal). Portanto, é um riquíssimo objeto de estudo.

Para suporte teórico, recorremos aos trabalhos de Debord (1997), Kellner (2006) e Wolff (2005) para tratarmos da questão do espetáculo, e Balogh (2002), Dayan e Katz (1999) quanto às narrativas.

\section{O espetáculo e os guiões: competição, conquista e coroação nos conteúdos circulados pelas mídias}

A Revolução Industrial provocou impactos não somente nos meios de produção, isto é, na economia, mas também na cultura e nas relações entre os indivíduos em sociedade. A inovação tecnológica, a produção em série, o trabalho alienado, o fetiche da mercadoria marcam a transição da sociedade moderna para uma sociedade do espetáculo. 
A humanidade tem convivido com o espetáculo desde os tempos pré-modernos. No entanto, ele intensificou-se com o surgimento das indústrias culturais, que, segundo Kellner (2006, p. 119), “[...] possibilitaram a multiplicação dos espetáculos nos novos espaços midiáticos e em site, e o espetáculo em si tornou-se um dos princípios organizacionais da economia, da política, da sociedade e da vida cotidiana."

Os atuais empreendimentos comerciais têm se baseado, principalmente, numa "economia de entretenimento", ou seja, na obtenção do lucro através da produção e circulação de produtos de diversão. Assim, os setores mais importantes da economia nacional são a televisão, o cinema, os parques temáticos, os videogames, os cassinos, entre outros.

Se por um lado, crescem a produção e a circulação desses produtos da indústria cultural, por outro, o número de corporações reduz-se cada vez mais, num processo de sinergia. Kellner (2006, p. 124) diz que a síntese da mídia, do computador, do entretenimento e da informação sugere uma nova "sociedade de infoentretenimento".

Contudo, a cultura do espetáculo não está presente apenas na economia, mas ela expandiu em todos os aspectos da vida - na política, na moda, no teatro, no cinema, no esporte, na arte, etc. Desse modo, “[...] já não existe nada, na cultura e na natureza, que não tenha sido transformado e poluído segundo os meios e os interesses da indústria moderna" (DEBORD, 1997, p. 173).

Debord (1997, p. 171) define o espetáculo como “[...] o exagero da mídia, cuja natureza, indiscutivelmente boa, visto que serve para comunicar, pode às vezes chegar a excessos." Sem dúvida, com os meios de comunicação mediada, foi possível reproduzir os conteúdos, conservá-los (o que antes ficava a cargo da memória), e fazê-los circular em um público maior, ou seja, o acesso ao conhecimento, à informação e à cultura tornou-se mais fácil e de domínio público. Porém, ao mesmo tempo, que os meios de comunicação mediada promovem uma democratização, também estimulam o consumo de produtos culturais, propõem certo padrão, pondo fím à diversidade, e reduzem os conteúdos a um jogoespetáculo, em que o telespectador é levado a um estado de relativa passividade e voyeurismo.

A sociedade do espetáculo é, portanto, fruto das transformações, as quais a sociedade foi sofrendo e das necessidades desse homem moderno. $\mathrm{O}$ trabalho industrial nos grandes centros urbanos possibilitou uma série de mudanças nos hábitos dos indivíduos, principalmente no que diz respeito ao lazer. Para o homem do campo, o trabalho fazia parte de sua vida diária, não havia um tempo para o descanso, e sim para as festas - folclóricas e religiosas. Mas isso foi enfraquecendo com a organização moderna e a divisão do tempo livre 
em fim de semana, férias. E aquele tempo da participação em atividades coletivas passou a ser um tempo da individualidade e do consumo.

Além disso, temendo a violência dos grandes centros urbanos, os indivíduos viram nos meios de comunicação mediada muito além de um meio de informação, mas um seguro modo de lazer e entretenimento. A televisão aos poucos foi se inserindo nos lares, ocupando o centro da sala até chegar ao quarto, no qual cada pessoa assiste sozinha aos programas.

Ao lado desta, há também a internet, que reúne várias mídias em um único aparelho, o computador. $\mathrm{Na}$ internet, ao mesmo tempo que uma pessoa está lendo uma notícia, ela pode acessar fotos daquele fato ou assistir a um vídeo, acessar outras informações relacionadas, dar sua opinião a respeito do assunto, através de chat, ou enquetes. Além disso, a leitura torna-se muito mais interativa e não segue necessariamente aquela leitura linear, de página por página, como em um jornal impresso.

Desse modo, deixamos a cultura de massa preencher todos os espaços da vida social, inclusive o lazer. Na sociedade do espetáculo, há uma preferência maior pela televisão, pelo videogame, pelo DVD, entre outros, do que pelas atividades que podem ser exercidas coletivamente.

O grande problema é que a relação entre o ser humano e a televisão (ou internet) pode tornar aquele um ser contemplativo, consumista e individualista. "Essa membrana invisível [tela] nos isola e ao mesmo tempo nos permite ver melhor e sonhar melhor, isto é, participar" (MORIN, 1967, p.75). Portanto, quando assistimos à televisão ou acessamos aos sites na internet, especialmente, aos conteúdos ficcionais (novelas), de reality shows ou publicitários, podemos transferir nossos impulsos e desejos para aquelas imagens que consumimos. Pois tais programas e conteúdos, até mesmo os jornalísticos, são produzidos, geralmente, para nos impressionar, para capturar nossa atenção e nos provocar interesse, emoção, contemplação.

Segundo Kellner (2006), há muitos níveis e categorias de espetáculo. Ele aponta como exemplo os megaespetáculos, que são eventos que têm uma cobertura exagerada pela mídia e, consequentemente, dominam as manchetes, o jornalismo e a agitação da internet.

Alguns rituais culturais, como as Olimpíadas, a Copa do Mundo, o Oscar e Emmy, entre outros, acabam tornando-se megaespetáculos, “[...] celebram os valores mais profundos da sociedade (por exemplo, a competição, o sucesso e dinheiro) [...]”, conforme explica Kellner (2006, p.128). E isto acaba revelando uma sociedade baseada na competição e na vitória.

Daylan e Katz (1999) entendem esses megaespetáculos por acontecimentos mediáticos, isto é, aqueles momentos históricos, tais como: competições políticas e 
desportivas, missões carismáticas e os rituais de passagem de grandes personagens, que são transmitidos em tempo real (ao vivo) pelos media, e que fazem parar todo país ou mundo.

Esses acontecimentos interrompem o fluxo televisivo, pois a emissão regular é suspensa até o término de sua emissão, e quando o acontecimento é muito importante sua interrupção atinge todos os canais. Além disso, normalmente, são organizados fora dos media; ou seja, ocorrem fora dos estúdios, pois não são eventos promovidos pelos media, mas eles são apenas chamados para fazer a sua cobertura.

Geralmente, esses acontecimentos são anunciados com antecedência, o que de certo modo cria uma expectativa na audiência e possibilita que os medias preparem a cobertura, sempre feita com reverência e cerimônia, até porque o próprio evento já é algo solene. Desse modo, a televisão raramente interfere na transmissão, somente quando é necessário explicar algum símbolo do acontecimento ou identificar alguma pessoa ilustre.

Esses acontecimentos tornam-se uma obrigação, isto é, todos se sentem no dever de assisti-los. Às vezes, as pessoas vestem-se até a caráter do evento, por exemplo, em época de Copa do Mundo, veste-se a camiseta da seleção nacional, etc.

Os acontecimentos mediáticos podem ser divididos em competição, conquista e coroação, pois são constituídos por esses três "Guiões" ou formas de narrativa. "A televisão utiliza estas fórmulas para contar as suas histórias, mas obviamente não foi ela a inventá-las" (DAYLAN e KATZ, 1999, p.39), essas estão presentes em narrativas primárias como nos mitos, nas histórias infantis, nos livros de história, e como veremos também no noticiário do vestibular.

\section{O arcabouço teórico da semiótica narrativa greimasiana}

Balogh (2002) comenta que as antigas narrativas ainda permanecem em nossa sociedade, constituindo os roteiros ficcionais da televisão, tais como as novelas. Contudo, transformadas por novas formas de recepção e veiculação, uma vez que a narrativa é descontínua e interrompida pelos comerciais.

Há uma gama de gêneros, nos quais o relato está presente, por exemplo, no mito, na lenda, na fábula, na novela, nas tiras cômicas, nas notícias policiais, entre outros. Ele está presente em todos os tempos e espaços, segundo Barthes (1970) apud Balogh (2002).

Através dos estudos da semiótica narrativa greimasiana, que retoma aos trabalhos de Propp, pôde-se compreender o que constitui uma narrativa e como ela se organiza. Segundo Balogh (2002), um objeto cultural, independente de seu suporte, pode ser descrito com uma 
narrativa, se tiver uma temporalidade, marcada por um antes e um depois, se for finito, tiver começo e fim, e se possuir um esquema mínimo de personagens, que realizem performances (ações), dando andamento à história.

A sequencialidade das performances do herói para atingir seu objetivo é caracterizada pelo seu aspecto dinâmico como um processo de melhoria ou de degradação. Quanto aos atores e atuantes, Greimas (1996) apud Balogh (2002, p. 58) elabora um modelo atuacional, no qual, destacam-se seis atuantes: o sujeito $(\mathrm{S})$ e o objeto $(\mathrm{O})$, que estão no eixo do querer e são responsáveis pelo conteúdo do programa narrativo $(\mathrm{PN})$, pois, o objeto ao ser desejado pelo sujeito dá início a uma busca; o destinador e destinatário, no eixo do saber, e o ajudante e oponente, no eixo do poder.

Balogh (2002) comenta que as narrativas podem ser vistas a partir da alternância de predicados estáticos e dinâmicos. Os primeiros constituem os enunciados de estado, que dizem respeito à relação do sujeito com o objeto, na qual, pode-se identificar enunciados conjuntivos ou disjuntivos. Já os predicados dinâmicos constituem os enunciados funcionais, que dizem respeito às realizações e, portanto, a transformação acontece neles. As narrativas podem ser de realização ou virtualização, conforme a posse do objeto.

Em geral, a maioria dos programas narrativos (PN) tem quatro fases: (i) manipulação, na qual, o personagem ou sujeito (S) deseja um objeto, sendo que este desejo pode nascer dele mesmo (automanipulação) ou pode ser levado a ele por outro personagem (destinador da manipulação); (ii) qualificação, para que o sujeito execute ações para obter o objeto, é preciso que ele tenha aptidões ou competência para isto; (iii) ação, o sujeito parte para a ação, performance, que além de ser o momento principal da narrativa, é também responsável pelas transformações; (iv) sanção, é o término das ações e, portanto, a conquista do objeto, recebendo o sujeito uma sanção.

\section{A espetacularização na web do Vestibular da FUVEST e da Unicamp}

No dia 15 de novembro de 2009, o site do G1 publica a notícia Confira fotos da primeira fase do vestibular 2010 da Unicamp (1). Esta relatava sobre a realização da primeira etapa da prova da Unicamp e sobre a candidata, Graicy Vital, que foi eliminada do vestibular antes mesmo de resolver a prova, pois havia chegado atrasada no local e não pôde entrar. Além do texto escrito, havia 14 fotos do acontecimento, desde a chegada dos candidatos aos locais de prova, fechamento dos portões, até a realização das provas. 
Já no dia 19 de dezembro de 2009, dois jornais da Rede Globo, Jornal Hoje (2) e Jornal Nacional (3), transmitiram matérias sobre o vestibular da FUVEST. Em geral, mostraram cenas de salas de aula de cursinhos pré-vestibulares lotadas de alunos estudando e fazendo dinâmicas para relaxarem para os exames. Tais notícias, posteriormente, foram publicadas no site da Globo.com. Neste, o internauta tem a opção de assistir ao vídeo ou somente ler o texto escrito, que contém o mesmo conteúdo, exceto pelas imagens, que podem provocar outra recepção da notícia.

No dia anterior à realização das provas da primeira fase do vestibular da FUVEST, o site G1, publicou a notícia, Vestibulando deve aproveitar o sábado para checar onde ficará a prova da Fuvest (4), que continha várias informações sobre o acontecimento, tais como o número de inscritos e de vagas oferecidas, o horário, os locais de provas, as datas de realização do exame e divulgação dos resultados, a relação candidato/vaga dos cursos oferecidos, o que levar no dia da prova (documento, material e alimentos), e outros links relacionados.

No dia do exame, 22 de novembro de 2009, encontramos notícias nos sites do jornal Estado de S. Paulo (Estadão.com.br), Fuvest realiza hoje prova da $1^{a}$ fase às 13 h (5), e do jornal Folha de S. Paulo (FolhaOnline), Mais de 120 mil fazem $1^{\circ}$ fase da Fuvest hoje; prova começa às $13 h$ (6), nas quais identificamos novamente informações sobre o número de inscritos e de vagas oferecidas, o horário, os locais de provas e as datas de realização do exame e divulgação dos resultados. De diferente, a notícia do site Folha de S. Paulo disponibilizava um link, onde o leitor poderia consultar os locais de prova da primeira fase, e outro link, informando as linhas de ônibus que servem os locais dos exames.

Ainda no mesmo dia, acessemos o site do G1, cuja notícia, Prova da FUVEST começa a ser aplicada (7), era composta de um texto de um parágrafo, informando o horário em que os portões foram fechados, o prazo que os candidatos teriam para a realização do exame, as cidades onde o vestibular seria realizado e o número de inscritos. Além disso, a notícia avisava que o G1 iria disponibilizar a correção da prova elaborada por professores de cursinhos. E abaixo do texto havia várias fotos do evento, tais como: dos candidatos chegando ao local das provas, do trânsito confuso, dos candidatos conferindo a sala onde fariam a prova, dos portões dos locais de exame sendo fechados, dos alunos dentro da sala, dos materiais e alimentos levados por um candidato sobre a sua carteira, entre outras. Desse modo, parece que o G1 não queria deixar de registrar, através das imagens, cada detalhe daquele momento. 
No site UOL, encontramos muitas informações sobre o vestibular da FUVEST e links onde os leitores poderiam ter acesso às provas, aos gabaritos e ao manual do candidato. Além de várias dicas para os vestibulandos se saírem bem na prova, a notícia do UOL, Fuvest 2010: confira o gabarito e o caderno de prova da $1^{a}$ fase (8), trazia um comentário do estudante Miguel Haidar Rodrigues sobre a prova da primeira fase, e abaixo um link para os leitores opinarem sobre o que eles acharam sobre o exame daquele dia. Em seguida, breves comentários sobre as obras literárias que caíram nas questões do exame daquele dia e informações sobre as mudanças na prova de segunda fase e sobre o cálculo dos bônus que substituíra a nota do Enem, que naquele ano não seria adotada pela USP.

O Estadão, no dia 14 de dezembro de 2009, divulgou a lista de aprovados para a segunda fase do vestibular da FUVEST e os novos locais de realização das provas. A notícia, Fuvest divulga lista de aprovados para segunda fase (9), também aproveitou para comentar as mudanças nas provas da segunda fase, nas quais os alunos tiveram que fazer questões de todas as disciplinas e não apenas das matérias especificas. Para esta segunda fase, disputaram as vagas 35.588 candidatos, além de 2.380 treineiros, isto é, alunos que ainda estão cursando o ensino médio e que fazem o vestibular somente como um treino.

No site G1, a notícia (10) que encontramos, nesse dia, comentava sobre a aprovação do candidato Gil Rugai, acusado de assassinato. Já a noticia Lista de aprovados para segunda fase da Fuvest tem mais de 37 mil nomes; confira (11), do site da FolhaOnline, divulgava além das novas datas das provas e números de candidatos, a lista dos convocados e dos locais de realização do exame. Enquanto isso, no site da UOL, a matéria, Fuvest inicia segunda fase neste fim de semana; prepare-se (12), além de trazer as mesmas informações contidas nas notícias publicadas nos outros sites, prometia que ao término de cada exame, o site exibiria correções das questões feitas por professores do curso objetivo de São Paulo. Este ainda disponibilizava uma porção de links relacionados com essa temática, em "Leia mais" e um quadro com 10 dicas para os vestibulandos se prepararem para os exames.

No dia 2 de janeiro de 2010, O Jornal Nacional transmitiu outra matéria (13) sobre o vestibular da FUVEST, novamente mostrando os alunos se preparando para as provas a serem realizadas nos três dias seguintes, no caso da USP, e nos quatro dias, da Unicamp. Desta vez, a fase seria mais cansativa, pelo fato de acontecer em mais de um dia da semana. Por isso, foi denominada de maratona ${ }^{4}$ pelo jornal.

\footnotetext{
${ }^{4}$ Segundo o míni Houaiss dicionário da Língua Portuguesa, o termo maratona significa uma prova de corrida a pé, de longo percurso ou, num sentido figurado, qualquer competição que exija grande resistência ou atividade longa e intensa.
} 
Nesse mesmo dia, os sites do FolhaOnline (14) e Estadão (15) publicaram novamente notícias sobre os exames. Dessa vez, comentando sobre como seriam as provas dessa fase. Porém, na notícia do Estadão foram citadas a opinião dos coordenadores dos cursinhos, Anglo e Etapa, que acreditam que com as mudanças nas provas da segunda fase, entre elas, a eliminação dos pontos da primeira fase, os candidatos passaram a ter as mesmas condições de aprovação. Contudo, aqueles que tiveram uma boa pontuação na primeira fase não gostaram muito das mudanças, como mostra a notícia, através do comentário de Luccas Antonio, aluno do Anglo, em entrevista ao site. Já outros aprovaram a mudança, como a candidata Gabriela Mendonça, que passou em cima da média para a segunda fase.

Além desses sites jornalísticos, acessamos os sites de dois cursinhos populares de São Paulo, Anglo e Etapa. Em geral, o que nos chamou a atenção nesses dois sites foi a divulgação que esses cursinhos fazem dos seus alunos aprovados, a fim de fazerem seu marketing como estabelecimento de ótimo ensino.

O cursinho pré-vestibular Etapa possui um jornal, Jornal do Vestibulando (16-17), no qual uma das seções é de entrevista com ex-alunos do cursinho que foram aprovados no vestibular - esse conteúdo também está disponível na página do cursinho online. De certa forma, as entrevistas nessa seção servem como testemunho sobre a eficaz do cursinho na preparação dos seus alunos para o vestibular.

Já o Anglo (18), pelo menos no último ano, organizou uma festa para seus alunos aprovados no vestibular, que foi filmada, e o vídeo encontra-se disponível em seu site e também no Youtube. Aqui, observamos novamente uma espécie de promoção do cursinho através da aprovação dos seus alunos no vestibular.

Portanto, analisando as notícias sobre o vestibular da FUVEST e da Unicamp e dos sites desses cursinhos pré-vestibulares, vimos como o ingresso ao ensino superior, por meio do Processo Seletivo do Vestibular, tornou-se um grande acontecimento noticioso para mídia, que aproveita para espetacularizá-lo, através de coberturas exageradas sobre o assunto. No caso da web, isso se observa, especialmente, nos vários links disponíveis, tais como, de dicas de como os vestibulandos devem se preparar para o vestibular, de qual ônibus eles devem pegar para chegar ao local da prova, bem como das listas dos aprovados, uma vez, que os candidatos têm acesso a elas pelo site da FUVEST.

Além disso, as mídias têm feito cada vez mais um jornalismo voltado para a linguagem não-verbal, ou seja, para um excesso de imagens, como podemos perceber no site do G1. A imagem tem sido muito explorada pelas mídias, porque ela "parece remeter necessariamente e como que naturalmente àquilo que ela representa" (WOLFF, 2005, p. 24), 
ou seja, a imagem não explica, não descreve, não diz nada, mas mostra. Assim, temos sempre a impressão que aquilo que vemos é realmente a verdade. Wolff (2005) diz que o poder da imagem está justamente neste seu defeito, isto é, de jamais poder dizer: o conceito, a negação, o possível, o passado e o futuro.

Assim, observamos também que as imagens sobre o vestibular tentam, por vezes, exploram o emocional daqueles que estão acessando aquele conteúdo, como na foto de Graicy Vital chorando por não conseguir chegar a tempo para prova da Unicamp, ou as cenas lotadas das salas dos cursinhos pré-vestibulares, mostradas nas matérias do jornal Hoje e Jornal Nacional, às vésperas do exame.

Sem contar que essas mídias acabam por (re)produzir uma identidade do candidato como um herói que consegue ser aprovado no Processo Seletivo do Vestibular, seja porque este tem capacidade, ou porque contou com ajuda de um cursinho, Anglo ou Etapa, que o preparou para esta grande conquista. Desse modo, o vestibular pode ser descrito a partir de uma grande narrativa, onde se encontram os guiões da competição, conquista e coroação e, na qual, refletem-se os valores (dinheiro e status) da nossa sociedade. E o jornalismo, de certa forma, segue essa lógica narrativa ao noticiar o Processo Seletivo do Vestibular. Primeiramente, os jornais noticiam o número de candidatos que disputarão às pouquíssimas vagas nas universidades (competição). Em seguida, divulgam a relação dos candidatos aprovados (conquista) e, consequentemente, esses são exaltados pelos jornais, através das notícias sobre os trotes, e, principalmente, nos anúncios publicitários dos cursinhos prévestibulares (coroação). Tentaremos no item que segue analisar mais detalhadamente o percurso desta narrativa do vestibular.

\section{Vestibular: a grande narrativa da pós-modernidade}

Nessa sociedade pós-moderna, culturalmente marcada pela valorização dos títulos e das profissões de carreira acadêmica (meritocracia), o vestibular pode ser descrito como um percurso narrativo, pelo qual a maioria dos jovens que concluem o ensino médio passa, em busca de uma carreira profissional bem-sucedida. Desse modo, a aprovação no vestibular é a narrativa de conquista de muitos brasileiros e, que, muitas vezes, é divulgada nas mídias.

No percurso narrativo do vestibular, identificamos o estudante que deseja uma vaga para fazer um curso superior. Temos, então, que o sujeito é o estudante e o objeto é a vaga para o curso superior. De acordo com Balogh (2002, p. 61): 
Cada narrativa nos mostra um microuniverso de valores que em geral refletem os valores da própria cultura em que ela se insere. Os personagens desejam aquilo que é socialmente valorizado (amor, dinheiro, fama, poder etc.). Desse modo, os objetos do desejo são, em geral, cobiçados, almejados, por mais de um personagem.

Assim, geralmente o sujeito deseja uma vaga em uma universidade bem conceituada e também uma vaga para um curso superior cuja carreira profissional tem certo status na sociedade e/ou é bem remunerada. Logo, esse objeto será cobiçado por um número maior de candidatos.

Um dos maiores vestibulares do país é o da FUVEST. No processo Seletivo de 2010, conforme divulgado no site do G1, na notícia Vestibulando deve aproveitar sábado para checar onde fará a prova na FUVEST, 128.144 candidatos disputaram 10.812 vagas, distribuídas 10.622 na Universidade de São Paulo (USP), 100 na Faculdade de Ciências Médicas de Santa Casa de São Paulo e 90 na Academia da Polícia Militar do Barro Branco. Os cursos mais concorridos foram oficial da Polícia Militar do Estado de São Paulo (43,58 candidato/vaga) e medicina (41,73 candidato/vaga).

Assim, para obter o objeto de desejo, os sujeitos partem para a ação, desencadeando o plano da narrativa que é a aprovação no vestibular da FUVEST ou da Unicamp. A performance do sujeito consiste, sobretudo, em estudar muito. Abaixo, destacamos um fragmento de uma das entrevistas do Jornal do Vestibulando, que exemplifica bem o que comentamos:

\begin{abstract}
Na minha opinião, se você tem um projeto, se deseja uma coisa para sua vida, para sua carreira, tem de acreditar que vai dar certo. Se não acreditar, você vai esmorecer no meio do caminho, não vai se dedicar, vai faltar à aula, não vai fazer simulado, vai deixar de estudar. E não vai conseguir um bom resultado. No meu caso, eu investi uma coisa importante para mim, que é meu tempo, minha própria qualidade de vida. $\mathrm{Eu}$ trabalho o dia inteiro, à noite poderia estar em casa com a família, no final de semana poderia estar com meus filhos, e estava aqui no cursinho fazendo aula de reforço, simulado (Francisco Bonomi em entrevista ao Jornal do Vestibulado de 27/08 a 09/09).
\end{abstract}

Para estudar muito e ser aprovado, o candidato pode recorrer aos cursinhos prévestibulares que oferecem um bom preparo para o Processo Seletivo do Vestibular, visto que contam com bons profissionais e materiais didáticos adequados aos conteúdos que caem no vestibular. Pelo menos é o que dizem as propagandas, e o que fica evidente nesse comentário de um ex-vestibulando ao jornal do cursinho Etapa:

Ao vir para São Paulo, você tinha base para encarar um vestibular de Medicina?

Não. Em Glória de Dourados, o ensino não é muito forte e eu não tinha noção de como era o vestibular da Fuvest. Mas eu era o melhor da sala e achava que ia passar. Ao terminar o colegial, prestei vestibular na Universidade Federal do Mato Grosso 
do Sul. Não passei. Aqui é que eu vi que estava em um nível muito baixo. Eu era o pior, vamos dizer assim, para prestar Medicina. Antes, eu estudava para prova do dia seguinte, o que é uma coisa bem comum, mas não é muito certo para o vestibular (Edelvan Gabana em entrevista ao Jornal do vestibulando de 04/06 a 17/06).

Observamos nesse depoimento que o candidato queria prestar o vestibular para medicina (manipulação). A entrevista conta que o candidato morava na cidade Glória de Dourados, Mato Grosso do Sul, e trabalhava ajudando o pai na roça. Como mostra a fala do candidato, quando ele tentou o vestibular pela primeira vez, pensou que estava preparado, pois era o primeiro da turma (qualificação). No entanto, foi reprovado. Não desistindo do seu sonho, ele mudou-se para São Paulo e inscreveu-se no cursinho Etapa, para prepara-se melhor para o Vestibular da Fuvest (ação). No terceiro ano de cursinho, Edelvan consegue ser aprovado em $5^{\circ}$ lugar em Medicina na USP/Pinheiros e em mais outras seis instituições de ensino Superior (sanção).

Outro fator que ajuda na aprovação do vestibular é o Exame Nacional do Ensino Médio (Enem), principalmente, para os alunos da rede pública. Naquela época, de acordo com o desempenho nesse exame, o aluno pode obter até $6 \%$ de bônus na nota. Só que nesse processo Seletivo de 2010, o resultado no Enem não foi aceito pela USP, pelo atraso da realização da prova, por causa de fraude. Mas, para não prejudicar os alunos, a USP criou uma fórmula matemática que calcula a bonificação com base no desempenho da primeira fase da FUVEST, explica a notícia já mencionada do G1.

Contudo, a notícia que foi ao ar no Jornal Nacional, no dia 19 de novembro de 2009, posteriormente postada no site do mesmo, dizia que "mais do que nunca os alunos precisam dos votos de boa sorte. Porque o ano não foi fácil. 'Teve o Enem, que a prova não foi feita, aí teve a gripe, que atrasou a aula também', lembrou o estudante Otavio Costa".

Desse modo, a notícia aponta a não utilização da nota do Enem como um empecilho que pode prejudicar o estudante (herói) na sua performance de obter a aprovação na FUVEST/2010. Em seguida, mostra as salas lotadas dos cursinhos, onde alunos estudam às vésperas da primeira fase do vestibular, marcada para o domingo, dia 22.

\footnotetext{
Além da ansiedade natural às vésperas do maior vestibular do país, os alunos têm outro motivo para estar na sala de aula até a última hora. É que a USP e outras universidades desistiram de usar o Enem em seus processos seletivos e, com esses pontos a menos no Vestibular, é preciso estudar mais. [...] Em um cursinho popular os professores não têm dúvida de que os alunos de escolas públicas serão prejudicados. Mas agora é encarar o vestibular do jeito que está aí, conter o nervosismo, cruzar os dedos e acreditar. [...] Sacrificar o feriado, redobrar a atenção, aprender alguma coisinha a mais e sonhar. "O meu sonho no futuro é trabalhar na área de tecnologia dos Estados Unidos, é o meu sonho” (Jornal Nacional).
} 
Novamente, tem-se a ênfase na ação, que consiste em estudar muito e a todo o momento, o que chega a ser um sacrifício. Sem contar que nesse trajeto podem acontecer muitas eventualidades para prejudicar o aluno, como foram naquele ano, a gripe suína e a fraude no Enem.

Mesmo depois, do que o estudante herói já lutou para realização de um sonho, este poderá não se concretizar. Por isso, nesse momento de sua narrativa, ele conta apenas com sua sorte para conquistar o tão desejado objeto, de acordo com o Jornal Nacional.

"O essencial de todos os modelos narrativos é que eles giram em torno das ações dos personagens. As ações executadas pelos personagens para atingir os seus objetivos constituem o cerne da narrativa", segundo Balogh (2002, p. 61). Desse modo, observamos que as notícias sobre o vestibular enfatizam, especialmente, as ações dos estudantes no sentido de obter a aprovação.

Em outra matéria do Jornal Nacional, transmitida no dia 2 de janeiro de 2010, um dia antes da segunda fase do vestibular, também postada no site, dois alunos aprovados, Felipe Ramires Miguel, primeiro lugar em economia da USP, e Francisco de Souza, aprovado em medicina, contam suas experiências no Processo Seletivo da FUVEST, orientando como proceder durante a prova e ensinando estratégias de chute. Nota-se aqui o destaque nas ações desses estudantes que conseguiram chegar vitoriosos no final dessa narrativa do vestibular e que hoje servem de modelo para aqueles que ainda estão construindo suas histórias de conquista no vestibular da FUVEST. Esta é a mesma estratégia utilizada nas entrevistas do Jornal do Vestibulando do cursinho Etapa.

Outra forma de destacar as ações é dando dicas para os estudantes se saírem bem no vestibular. A matéria, Fuvest 2010: confira o gabarito e o caderno de prova da $1^{a}$ fase, publicado no site UOL, dia 22 de novembro de 2009, traz uma lista de links com dicas do que os candidatos podem fazer para se prepararem para segunda etapa do exame. O mesmo pode ser identificado em outra matéria, Fuvest inicia segunda fase neste fim de semana; preparase, publicada no mesmo site, no dia 15 de dezembro de 2009.

Pela natureza do Processo Seletivo do Vestibular, sabemos que o número de vagas não é o suficiente para a demanda, assim ele pode ser narrado em termos de uma competição, na qual os candidatos lutam pela obtenção do mesmo objetivo, ingressar na USP ou Unicamp.

O vestibular da FUVEST e da Unicamp é um evento anual. Todos, especialmente os candidatos, sabem as regras do Processo Seletivo para o ingresso ao ensino superior. A princípio, parece que todos têm a mesma probabilidade de aprovação, mas sabemos que os 
candidatos que têm um nível socioeconômico baixo, que vêm de escolas da rede pública e que trabalham e, por isso, não podem estudar em tempo integral são reprovados no vestibular, especialmente, da FUVEST e da Unicamp, que são os mais concorridos do país. Sem contar que as provas não são classificatórias, mas eliminatórias. Assim, podemos dizer que o oponente é, ao mesmo tempo, as provas do Processo Seletivo do Vestibular e os demais candidatos às vagas, daí, a relação candidato/vaga.

Então, o drama é o seguinte: Quem será aprovado? Aquele que estudar mais e em bons colégios ou fizer um cursinho pré-vestibular? Ou aquele que tiver bastante sorte?

Desse modo, os candidatos se preparam durante o ano todo e da maneira que podem: frequentam aulas nos cursinhos pré-vestibulares, dedicam-se exclusivamente ao estudo, inclusive, nos finais de semana, fazem exercícios para evitar a tensão das provas, etc. Mas, só serão aprovados os melhores. E quem for reprovado poderá se inscrever no Processo Seletivo do Vestibular do próximo ano.

Abaixo, um fragmento em que o ex-vestibulando aponta a prova como inimigo e também diz que aquele que já tentou a prova antes tem vantagem sobre aquele que faz pela primeira vez, ou seja, este é um inimigo fraco, fácil de derrubar, pela sua inexperiência. Assim, não ser aprovado logo de primeira tem seu aspecto positivo, pois aumenta as possibilidades de aprovação. Assim, não é à toa que muitas pessoas têm feito o vestibular como treineiros.

\footnotetext{
Algumas pessoas estão prestando o vestibular de novo, por não terem tido sucesso no exame anterior. Você acha que a experiência anterior conta positivamente?

Quem tentou no ano passado e não conseguiu já conhece o adversário a ser batido: a prova. Já tem a experiência de saber o que faltou. E essa é uma vantagem em relação a quem tenta pela primeira vez. Agora tem de acreditar, manter a confiança e a determinação (Francisco Bonomi em entrevista ao Jornal do Vestibulado de 27/08 a 09/09).
}

Na notícia do Jornal Nacional, Jovens recomeçam a maratona do vestibular, um dos aprovados no curso de medicina compara o vestibular a uma guerra: "tem que ter estratégia, treinamento difícil e combate fácil. A recompensa é muito grande".

Mas o Processo Seletivo do vestibular da FUVEST também pode ser narrado como uma conquista, pois exige do candidato capacidade, dedicação ao estudo, realização das provas, dentro do prazo e horário estipulado, superação da ansiedade, do medo, isto é, do psicológico e do emocional e, por fim, aprovação em todas as duas fases, que somam quatro 
dias de prova, para USP, e cinco, para Unicamp. Desse modo o drama da narrativa em questão é: será que o candidato conseguirá a vaga na FUVEST ou Unicamp?

O Jornal Hoje, do dia 20 de novembro de 2009, também noticia sobre o vestibular da FUVEST, destacando o que os alunos estão fazendo para serem aprovados. A imagem é a cena de uma sala de cursinho lotada, os alunos estão com os braços levantados para o alto. E, então, o jornalista faz duas perguntas para o telespectador: "os alunos do cursinho estão fazendo o quê? Às vésperas do vestibular mais importante do país, a turma está brincando?”. E responde dizendo que eles estão aliviando o estresse, relaxando. Por outro lado, quando a brincadeira termina, uns começam a chorar, como a candidata a medicina Kelly Firsoff, e outros a estudar. Assim, duas ações são destacadas: estudar e exercitar o corpo, sendo esta última essencial, nesse momento, para que o candidato realize uma boa prova no dia seguinte. Dois professores desse cursinho aconselham os candidatos a não se preocuparem em estudar aquilo que não sabem, mas revisar o conteúdo e relaxar.

O jornal compara o vestibular a uma maratona quando comentam: "esse é o primeiro passo na carreira de todos eles. A dúvida é o que fazer pra não tropeçar logo na largada". Essa mesma comparação é identificada na matéria do Jornal Nacional do dia 2 de janeiro de 2010, já comentado. No site G1, a reportagem ganha o título: Jovens recomeçam maratona do vestibular, referindo-se a segunda fase pela qual os alunos aprovados iriam realizar naquele fim de semana.

A notícia também inicia com a cena de uma sala de aula de cursinho lotada de alunos. O professor no quadro explica uma série de exercícios. E o jornal aproveita para fazer a comparação entre o vestibular e uma maratona:

\footnotetext{
O professor passa a bola: 'Como é que eu vou fazer para achar esse ponto P?. O ponto de partida desse campeonato é concentração. "Tem que pensar que é o final, que a gente vai conseguir, que vai ter um resultado positivo no final", afirma Fernanda Santos, de 26 anos. Mas a essa altura, depois de tantas provas, o fôlego dos atletas do vestibular está no fim. "Dá uma cansada sim", conta o Fernando Kume, 17 anos (Jornal Nacional) [grifo nosso].
}

A câmera focaliza no meio daquela multidão um aluno deitado sobre os livros, provavelmente dormindo, confirmando o que foi dito sobre o cansaço, depois de tanto estudo, e de uma etapa de provas. Em seguida, o repórter Alan Severiano comenta que "com a divulgação dos resultados, essa expectativa vai virar frustração para uns e alívio para outros. 
Afinal, o que é decisivo para ser aprovado?". Tal pergunta compreende o drama dessa narrativa de conquista que é o vestibular.

O Jornal Nacional do dia 2 de janeiro termina a notícia mostrando as experiências, já comentadas aqui, de quem terminou vitorioso. Enquanto isso, a notícia, Confira fotos da primeira fase do vestibular 2010 da Unicamp, publicada no site do G1, no dia 6 de dezembro de 2009, conta a narrativa da vestibulanda Graicy Vital, 17 anos, que chegou atrasada ao local da realização da prova e foi barrada na entrada.

\footnotetext{
Ela saiu às $12 \mathrm{~h} 40$ de casa, no Tucuruvi, na Zona Norte de São Paulo, com a mãe e o filho recém-nascido, Enzo, de apenas 14 dias. Mesmo estando de carro, encontrou trânsito pela frente e não chegou a tempo no prédio na Aclimação, região central, onde faria a prova da primeira fase. Durante o exame, o plano de Graicy era deixar o bebê aos cuidados da mãe. Chorando muito, ela não se conformava de ficar de fora do vestibular. "Preciso de um emprego, preciso de uma ocupação", disse a estudante, que tentava uma vaga em medicina (G1).
}

Terminava, naquele instante, o sonho da personagem. Com a imagem do filho no colo e chorando, o G1 narra o final triste de uma história.

Esse site, no dia 15 de dezembro de 2009, também narra a conquista de aprovação no vestibular da FUVEST do candidato Gil Rugai, acusado de matar o pai e a madrasta em 2004. Segundo o site, o candidato ficou preso entre 2004 e 2006, tendo sido concedida a liberdade provisória. Mas esta foi revogada em 2008, quando Rui teria se mudado de São Paulo para o Rio Grande do Sul para estudar. Contudo, a Justiça teria entendido isto como uma tentativa de fuga. Além da FUVEST, Rui também foi aprovado na segunda etapa da Universidade Estadual do Rio de Janeiro (UERJ).

Em geral, os leitores se impressionam com histórias de jovens que conquistaram uma vaga nas universidades, sobretudo se este foi aprovado em primeiro lugar em um curso muito concorrido em uma universidade Federal ou Estadual e, ainda mais, se este veio de escola da rede pública e possui um nível socioeconômico baixo. Uma das entrevistas do Jornal do Vestibulando tem o seguinte título: "Da roça ao $5^{\circ}$ lugar em Medicina na USP/Pinheiros". O jornal explora o fato do ex-candidato aluno do cursinho ter crescido e morado na zona rural do Mato Grosso. É um título que desperta atenção e que pode fazer com que o leitor tenha certo carisma com aquele personagem.

Com a conquista da aprovação no vestibular, o candidato herói é então coroado. Porém, mesmo depois de passar por todo um ritual de entrada na universidade que é a 
realização e aprovação nas provas do vestibular, o herói passa ainda por um ritual de celebração, o trote. Este consiste de várias brincadeiras que os universitários fazem os calouros $^{5}$ (ou bicho) participarem durante a primeira semana de aula, entre elas, andar todo sujo de tinta pelas ruas. Para os meninos, o trote, principal, é raspar o cabelo. Contudo, ultimamente, os calouros também têm recebido esse trote da família e dos amigos.

Esse ano fui de novo esperar a lista na casa da minha namorada. Foi muito legal, ela já começou a raspar minha cabeça, liguei para minha mãe, começou aquela choradeira. Não tem como descrever a emoção de passar no vestibular. Não é só um peso que você tira, é uma vida diferente que se abre para você. Uma emoção muito grande, não tem com descrever. Maravilhoso (Edelvan Gabana em entrevista ao Jornal do Vestibulando de 04/06 a 17/06).

Portanto, esse é um momento de festa, de comemoração, ou seja, de receber a sanção pelo esforço empreendido ao longo do ano. Para ilustrar o que estamos dizendo, selecionamos um vídeo postado no site do cursinho pré-vestibular Anglo no dia 9 de fevereiro de 2009.

O vídeo é a cobertura da festa que o Anglo organizou para comemorar a aprovação dos alunos no vestibular. Ele nos mostra os alunos se preparando para aquele ritual de coroação, ou seja, pintando, no rosto, com tinta, as siglas das universidades (ou curso), nas quais foram aprovados. Além disso, para o evento foi produzida uma camisa, a qual todos (alunos, funcionários e pais) estavam vestindo. Nesta estavam estampados, na parte da frente, os dizeres "Faça a festa" e a logomarca do cursinho, o leão, enquanto na parte das costas, os dizeres "Sonhei, estudei e batalhei passei!", além do nome do cursinho e outras informações.

Durante aquele momento os alunos dançavam ao som de um grupo de batuque, riam, posavam para câmeras fotográficas e davam entrevistas para uma equipe que fazia a cobertura desse vídeo para o cursinho. Além dessas cenas descritas, quem assiste ao vídeo, ouve a música Extravasa da cantora Cláudia Leite, que é uma música de axé, que remete ao carnaval da Bahia. Aliás, a festa bem parecia um carnaval, com direito até a balões caindo sobre as pessoas presentes. Ao final do vídeo, aparecem cortes de algumas entrevistas. Em geral, a repórter do Anglo perguntava ao calouro em qual universidade e curso ele havia sido aprovado e qual tinha sido a contribuição do Anglo para esta conquista. Todos os entrevistados haviam passado na USP e na Unicamp, em cursos concorridos, como medicina, nutrição e estatística. Todos responderam que estudar no Anglo havia garantido a aprovação no vestibular e ressaltaram, principalmente, a qualidade do material didático.

\footnotetext{
${ }^{5} \mathrm{O}$ candidato ao ser aprovado é denominado pelo termo 'calouro' ou 'bicho' que designa aquele que é novato na universidade.
} 
De certa forma, quando as mídias jornalística e publicitária resgatam essas histórias, elas acabam por criar também uma espécie de exibicionismo. Afinal, quem não gostaria de ter sua história de conquista contada para milhões de pessoas? E isto tudo pode despertar o imaginário daqueles que estão assistindo, pois também esses podem acabar sonhando em um dia também serem aprovados no vestibular ou de verem o (a) filho (a) conquistando uma vaga na universidade. Desse modo, "a cultura da mídia não aborda apenas grandes momentos da experiência contemporânea, mas também oferece material para fantasia e sonho, modelando pensamento e comportamento, assim como construindo identidades" (KELLNER 2006, 119).

\section{Considerações finais}

A partir dos dados obtidos nas análises das notícias e de outros materiais circulados na web sobre o vestibular da FUVEST e da Unicamp, é possível perceber que o vestibular tem sido espetacularizado tanto pela mídia jornalística quanto pelas publicidades de cursinhos prévestibulares. Como discute Dubord (1997), o espetáculo é a despolitização. Desse modo, enquanto aplaudimos e alegramos com as narrativas de conquista e coroação de alguns jovens brasileiros aprovados no vestibular, muitas vezes, deixamos de discutir questões sociais importantes relacionadas à Educação Formal e, principalmente, ao acesso público gratuito ao ensino superior que, infelizmente, é um processo totalmente excludente.

(Recebido em 02/12/2013, aprovado em 19/12/2013)

\section{Referências bibliográficas}

BALOGH, Ana Maria. Narrativa e ficção televisual. In: $O$ discurso ficcional na TV. São Paulo: EDUSP, 2002.

DAYAN, Daniel; KATZ, Elihu. Definição de acontecimento mediáticos: os dias festivos da comunicação social. In: . A história em directo. Coimbra: Minerva, 1999.

- O guião dos acontecimentos mediáticos: competição, conquista, coroação. In: A história em directo. Coimbra: Minerva, 1999.

DEBORD, Guy. A sociedade do espetáculo: Comentários sobre a sociedade do espetáculo. Rio de Janeiro: Contraponto, 1997.

KELLNER, Douglas. Cultura da mídia e triunfo do espetáculo. In: MORAES, Denis de (Org.). Sociedade Midiatizada. Rio de Janeiro: Mauad, 2006.

MORIN, Edgar. Uma cultura de Lazer. In: Cultura de Massa no Século XX-O

Espírito do Tempo. Rio de Janeiro: Forense, 1967. 
WOLFF, Francis. Por trás do espetáculo: o poder das imagens. In. NOVAES, Adauto (org.). Muito Além do Espetáculo. São Paulo: Editora Senac, 2005.

\section{Matérias citadas (internet)}

1. Confira fotos da primeira fase do vestibular 2010 da Unicamp. G1. São Paulo. 15 Nov. 2009. Disponível em:<http://g1.globo.com/Noticias/Vestibular/0,MUL1379805-5604,00CONFIRA+FOTOS+DA+PRIMEIRA+FASE+DO+VESTIBULAR+DA+UNICAMP.html> . Acessado em: 15. Nov. 2009.

2. Primeira fase da Fuvest acontece no domingo (22). Jornal Hoje. São Paulo. 19 Nov. 2009. Disponível em:<http://g1.globo.com/jornalhoje/0,,MUL138669816022,00PRIMEIRA+FASE+DA+FUV EST+ACONTECE+NO+DOMINGO.html>. Acessado 20 Nov.2009.

3. Alunos se preparam para o maior vestibular do país. Jornal Nacional. 19 Nov. 2009. Disponível em:<http://jornalnacional.globo.com/Telejornais/JN/0,,MUL138714910406,00ALUNOS+SE +PREPARAM+PARA+O+MAIOR+VESTIBULAR+DO+PAIS.html>. Acessado dia 20 Nov. 2009.

4. Vestibulando deve aproveitar o sábado para checar onde fará a prova da Fuvest. G1. São Paulo. $212009 . \quad$ Nov. Disponível em:< http://g1.globo.com/Noticias/Vestibular/0,,MUL1386938 5604,00.html>. Acessado em: 22 Nov. 2009.

5. Fuvest realiza hoje prova da $1^{a}$ fase às 13h. Estado de São Paulo. 22 Nov. 2009. Disponível em: <http://www.estadao.com.br/noticias/geral,fuvest-realiza-hoje-prova-da-1-fase-as13h,470266,0.htm>. Acessado 22 de novembro de 2009.

6. Mais de 120 mil fazem $1^{\circ}$ fase da Fuvest hoje; prova começa às 13 h. Folha de São Paulo. $22 \quad$ Nov. $2009 . \quad$ Disponível em: <http://www1.folha.uol.com.br/folha/educacao/ult305u655826.shtml〉. Acessado 22 de novembro de 2009.

7. Prova da FUVEST começa a ser aplicada. G1. São Paulo. 22 Nov. 2009. Disponível em:<http://g1.globo.com/Noticias/Vestibular/0,,MUL13880715604,00PROVA+DA+FUVES T+COMECA+A+SER+APLICADA.html>. Acessado 22 de novembro de 2009.

8. Fuvest 2010: confira o gabarito e o caderno de prova da $1^{\text {a }}$ fase. UOL. 22 Nov. 2009. Disponível em:<http://vestibular.uol.com.br/ultnot/2009/11/22/ult798u25412.jhtm>. Acessado 22 de novembro de 2009. 
9. Fuvest divulga lista de aprovados para segunda fase. Jornal Estado de São Paulo. 14 Dez. 2009. Disponível em:<http://www.estadao.com.br/noticias/suplementos,fuvest-divulga-listade-aprovados-para-a-segunda-fase,481602,0.shtm>. Acessado 15 Dez. 2009.

10. Gil Rugai passa na primeira fase da Fuvest. G1. 14 Dez. 2009. Disponível em:<http://g1.globo.com/Noticias/Vestibular/0,,MUL1415010-5604,00.html>. Acessado 15 Dez. 2009.

11. Lista de aprovados para segunda fase da Fuvest tem mais de 37 mil nomes; confira. Folha

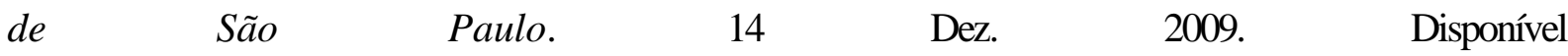
em:<http://www1.folha.uol.com.br/folha/educacao/ult305u666058.shtml>. Acessado 15 Dez. 2009.

12. Fuvest inicia segunda fase neste fim de semana; prepare-se. UOL. 02 Jan. 2010. Disponível em:<http://vestibular.uol.com.br/ultnot/2008/01/02/ult798u21686.jhtm>. Acessado 03 Jan. 2010.

13. Jovens recomeçam maratona do vestibular. Jornal Nacional. 02 Jan. 2010. Disponível em: <http://jornalnacional.globo.com/Telejornais/JN/0,,MUL1432953-10406,00-

JOVENS+RECOMECAM+MARATONA+DO+VESTIBULAR.html>. Acessado em 03 Jan. 2010 .

14. Segunda fase da Fuvest começa neste domingo. Folha de São Paulo. 02 Jan. 2010. Disponível em: <http://www1.folha.uol.com.br/folha/educacao/ult305u673775.shtml>. Acessado dia 03 Jan. 2010.

15. Segunda fase da Fuvest começa neste domingo. Estado de São Paulo. 02 Jan. 2010. Disponível em: <http://www.estadao.com.br/noticias/suplementos,segunda-fase-da-fuvestcomeca-neste-domingo,489737,0.shtm>. Acessado dia 03 Jan. 2010.

16. Da roça ao $5^{\circ}$ lugar em Medicina na USP/Pinheiros. Jornal do Vestibulando. De 04/06 a 17/06. Disponível em: <http://www.etapa.com.br/index.php>. Acessado dia 08 Jan. 2010.

17. Do etapa para a USP. De novo, 17 anos depois. Jornal do Vestibulando. De 27/08 a 09/09. Disponível em: 〈http://www.etapa.com.br/index.php〉. Acessado dia 08 Jan. 2010.

18. Festa dos aprovados! Anglo. 09 de fevereiro de 2009. Disponível em: < http://www.cursoanglo.com.br/WebStander/eventos/Index.asp?ID=102>. Acessado dia 01 de Nov. 2009. 